University of Nebraska - Lincoln

DigitalCommons@University of Nebraska - Lincoln

Faculty Publications in Educational

Administration

Educational Administration, Department of

Fall 2020

\title{
The Role of Mental Health Issues in Faculty-Led Short-Term Study Abroad
}

Kaleb L. Briscoe

Elizabeth Niehaus

Matthew Nelson

Angela Bryan

Follow this and additional works at: https://digitalcommons.unl.edu/cehsedadfacpub

Part of the Educational Administration and Supervision Commons

This Article is brought to you for free and open access by the Educational Administration, Department of at DigitalCommons@University of Nebraska - Lincoln. It has been accepted for inclusion in Faculty Publications in Educational Administration by an authorized administrator of DigitalCommons@University of Nebraska - Lincoln. 


\title{
The Role of Mental Health Issues in Faculty-Led Short-Term Study Abroad
}

\author{
Kaleb L. Briscoe \\ Mississippi State University \\ Elizabeth Niehaus \\ University of Nebraska - Lincoln \\ Matthew Nelson \\ University of Nebraska - Omaha \\ Angela Bryan \\ University of Nebraska - Lincoln \\ Correspondence - Kaleb Briscoe, kbriscoe@colled.msstate.edu
}

\begin{abstract}
Mental health issues in faculty-led short-term study abroad (FLSTSA) courses are becoming increasingly prevalent. To date, little is known about the role mental health issues play in study abroad courses, including the implications for student affairs practice. This study examines the role of mental health issues in faculty-led shortterm study abroad courses, from the perspective of the faculty instructors. Findings from this study provide a nuanced understanding of how student mental health issues shape study abroad experiences for the student experiencing mental health issues abroad, other students, and the faculty instructors.
\end{abstract}

As higher education institutions seek to increase the number of students participating in study abroad (American Council on Education, 2017), faculty-led, short-term study abroad (FLSTSA) courses are becoming increasingly popular (Institute for International Education [IIE], 2018; Tuma, 2007). According to recent data from the IIE (2018), $65 \%$ of U.S. students who study abroad do so through short-term programs. The majority of short-term

Published in College Student Affairs Journal 38:2 (Fall 2020), pp. 143-156.

https://doi.org/10.1353/csj.2020.0010

Published by Southern Association for College Student Affairs. 
programs are courses led by individual faculty members who take a group of students, often from the same home institution, abroad for a relatively short period of time and focus on specific course-based learning objectives (Forum on Education Abroad, 2011; Tuma, 2007).

With the popularity of FLSTSA courses, greater attention needs to be paid to how institutions can continue to provide the level of support services students typically have access to on campus, often provided by student affairs professionals. This is particularly true with regard to mental health services. The American College Health Association (ACHA, 2015) estimated that at least one in four students experiences some sort of mental health challenge during college. These mental health issues cannot be put on hold while students are abroad, and yet the traditional support systems available on campus (e.g., counselors, resident assistants, and advisors) are generally not present on short-term study abroad courses. Instead, faculty members leading these courses are responsible not only for teaching, but also for ensuring students' physical and mental health while abroad (Goode, 2007).

Despite the fact that students' mental health needs do not stop at the U.S. border, little is known about how mental health issues are playing out in short-term study abroad courses. In order for student affairs professionals to provide the resources that both students and faculty members need to support students' mental health, they must first understand what is happening while students are abroad and the role that mental health issues have in the experiences of those involved. As such, the purpose of this study is to examine the role of mental health issues in FLSTSA courses from the perspective of the faculty instructors.

\section{Students' Experiences with Study Abroad and Mental Health}

College students' mental health issues are becoming increasingly prevalent in short-term study abroad courses (Bathke \& Kim, 2016; Prince, 2015). Additionally, there has been an increase in the number of students seeking assistance and the severity of mental health issues (Holm-Hadulla \& Koutsoukou-Argyraki, 2015). The most common mental health issues encountered abroad include anxiety, depression, substance abuse, alcohol/drug abuse, psychosomatic problems, suicidal ideation, and personality disorders (Holm-Hadulla \& Koutsoukou-Argyraki, 2015; Prince, 2015). Although few studies have examined students' experiences with mental health issues in study abroad courses, a recent study by Bathke and Kim (2016) noted that the percentage of students facing mental health issues abroad is similar to the percentage who face mental health issues on campus. With one in four college students experiencing mental health issues on campus (ACHA, 2015), 
it is imperative to understand the role of students' mental health issues in study abroad course experiences.

Study abroad courses are challenging for all students, but the added stress of studying abroad can exacerbate students' existing mental health issues (ACHA, 2015). Moreover, cultural change can induce stress and the majority of students who have participated in study abroad report feelings of being stressed as a result of this (Ryan, \& Twibell, 2000). Psychological distress in particular such as culture shock and loneliness have been noted to impact students' overall ability to function while abroad, which triggers issues of anxiety and depression (Hunley, 2010). In addition, unfamiliar

environments and lack of familiar support systems such as clubs and organizations, fraternity and sorority life, and resident life can be particularly challenging for students with existing mental health issues in short-term study abroad courses (McCabe, 2005; Prince, 2015). Students with mental health issues who are studying abroad may feel isolated from family and friends, prompting increased anxiety (ACHA, 2015). Overall, adjusting to the differences between the U.S. and host country (e.g., living conditions, food, and friend groups) can be difficult for students with mental health issues and can contribute to their stress (Bathke \& Kim, 2016).

Mental health issues can be particularly challenging in short-term study abroad courses, as they can possibly influence those around them and have an effect on student-group interactions (McCabe, 2005). Previous research on study abroad has demonstrated the strong role of interactions with peers in students' experiences, learning, and development. For example, Jones et al. (2012) found that short-term immersion programs, including study abroad, provided opportunities for students to interact with peers who were culturally and racially different from themselves, in ways that facilitated their learning about difference. Jones et al. (2012) described that despite their short duration, these types of immersion experiences were characterized by "intense group dynamics" (p. 209). The intensity of the group dynamics in short-term study abroad programs means that it is important to consider the role of mental health issues on the entire group, not just the individual student.

\section{Faculty Members' Experiences with Study Abroad and Mental Health}

In addition to being an intense experience for students, teaching study abroad courses can also be a challenging experience for faculty members (Goode, 2007). When teaching abroad, faculty members take on a variety of additional roles over-and-above their normal responsibilities, such as serving as tour guides, disciplinarians, administrators, mentors, and counselors 
(Keese \& O'Brien, 2011; Wolf \& Archer, 2013). Because most college students are inexperienced travelers (Linder \& McGaha, 2013), faculty instructors spend numerous hours conducting pre-trip meetings with students (Brewer \& Solberg, 2010), often plan and coordinate all programmatic aspects of a study abroad course (Spencer \& Tuma, 2017), and must be prepared to support students through issues of culture shock and adjustment (Barbour, 2015).

Because they are the primary, and sometimes the only, institutional representative available to students in FLSTSA courses, faculty members are on the front lines when students experience issues abroad. The "on-theground assistance" that faculty members provide during FLSTSA courses (Keese \& O'Brien, 2011, p. 6) are similar to student affairs practitioners' roles on campus, which include responsibilities such as managing "student group dynamics, mental health, physical health, safety, and alcohol use" (Goode, 2007 , p. 155). These roles are often unfamiliar to faculty members, as on campus students typically have access to an array of student support services in these areas (Goode, 2007). While faculty members have a lot to gain from teaching short-term study abroad courses (Keese \& O'Brien, 2011), the multitude of roles and complexities related to students' mental health issues can be overwhelming (Goode, 2007).

Despite being in a position to respond to students' mental health needs abroad, faculty members are often not trained to do so (Barr, 2013; Keese \& O'Brien, 2011), necessitating partnerships with counseling center staff and other student affairs professionals on the home campus (Goode, 2007). For instance, college counseling professionals can offer instructors training on how to "recognize and respond to student mental health distress... because they better understand the prevalence and nature of student mental health needs" (Morse et al., 2017, p. 329). Counseling professionals can also work with faculty members to understand issues of confidentiality and legal requirements under the Americans with Disabilities Act (Morse et al., 2017). Morse et al.'s (2017) article also suggest that counseling centers can provide training to faculty members on how to recognize and address mental health concerns in students and empower them to assist peers with issues that may arise. Overall, faculty members may need to educate themselves on when and how to refer students to counseling as well as be prepared to address mental health issues while abroad through identifying resources (Prince et al., 2006). Specifically, Leggett (2012) noted "the goal is not to turn faculty members into therapists, but to enable them to spot the signs of distress, know the appropriate resources, and connect the person to help" (p. 12).

Counseling professionals and other student affairs practitioners providing support to faculty members abroad also need to be aware of the support faculty members themselves might need as they navigate difficult mental 
health issues (Bathke \& Kim, 2016). Faculty members may be experiencing the same culture shock, adjustment, and anxiety that students experience while abroad, and addressing students' mental health needs can cause additional stress for the faculty members involved (Barbour, 2015; Keese \& O'Brien, 2011; Prince, 2015). More severe mental health issues, such as depression and suicidal ideation, can have traumatic implications for the faculty members leading study abroad courses, increasing their own need for mental health support (Barbour, 2015; Prince, 2015).

In order for student affairs professionals to support students experiencing mental health issues abroad and assist faculty members who teach FLSTSA courses, they must first have an in-depth understanding of how mental health issues affect short-term study abroad courses. Therefore, the purpose of this study was to explore, from the perspective of faculty instructors, the role of student mental health issues in shaping the study abroad course experiences of the students experiencing mental health issues abroad, other students in the study abroad courses, and the faculty instructors themselves.

\section{Methodology}

This study stemmed from a larger sequential explanatory mixed methods study (Creswell, 2003) on instructors' approaches to teaching FLSTSA courses. The qualitative phase of this study, which provides the basis for this paper, employed a multiple case study approach (Merriam \& Tisdell, 2016; Stake, 2006). For this study, each individual faculty instructor who had taught and led a short-term study abroad course with students who had experienced mental health issues while abroad was a separate case. We chose to focus on faculty instructors because of their unique role overseeing course curriculum, logistics, and student support services in these courses, giving each instructor a birds-eye view of the entire course experience. By considering each faculty instructor as a case, we were able to explore each instructors' experiences in depth and to compare experiences across multiple cases (Stake, 2006), gaining insight into the role of mental health issues in the overall course experience.

\section{Case Identification}

We used a combination of information-rich cases and maximum variation sampling (Creswell \& Poth, 2018) to select individual cases that allowed us to explore the phenomenon of mental health issues in FLSTSA courses in depth. First, we used the results of a larger survey of faculty instructors

of short-term study abroad programs (see Niehaus et al., 2020, for more 
information on the survey data collection) to identify instructors who had indicated that they had some role in addressing students' mental health needs abroad. Within the group of instructors who had encountered student mental health issues abroad, we used maximum variation sampling to include instructors who (1) both had and had not felt prepared to address students' mental health needs abroad, (2) came from a variety of disciplines, and (3) taught courses in a variety of countries/regions. Participants included seven women and six men. Ten participants identified as White/Caucasian, two as Asian/Pacific Islander, and one as Hispanic. Participants came from across the U.S. and represented nine public universities, two liberal arts colleges, one community college, and one historically Black college. Participants were affiliated with a wide range of disciplines and had an array of professional experiences, including tenure-track, tenured, and non-tenure track faculty and staff members.

\section{Data Collection}

Consistent with multiple case study methodology (Stake, 2006), we used multiple forms of data to inform our understanding of each case. We relied primarily on a 45-60 minute in-depth interview with each participant, but also paired this with information from each participant's survey responses. In the interviews, participants were asked to describe what had happened during their course, with particular attention to describing specific mental health issue(s) that arose during the course; how they responded to the mental health issue(s); and the role, if any, of mental health issues on the experiences of the student(s) involved, other students in the course, and the participants themselves.

\section{Data Analysis}

Data analysis included both within-case and cross-case analysis (Stake, 2006). We began our within-case analysis with descriptive coding, which included summarizing key words and phrases (Saldaña, 2016). Using participants' survey responses and data coded in the interview transcripts, we then created individual case summaries highlighting the types of mental health issues that students experienced, faculty instructors' responses, and the role the students' mental issues had in the experiences of each participant and in the overall course (Stake, 2006).

Next, we conducted a cross-case analysis to explore the similarities and differences among the thirteen participants. We started by creating visual displays, which helped us view data in different ways and gave us a method to explore patterns and connections from our case summaries (Miles et al., 
2014). Identifying the main elements across participants, we focused on building our understanding of the role that mental health issues played in shaping the study abroad course experiences of all involved. We coded using colors as a form of visual representation to highlight aspects of each participants' story, including how these elements were viewed similarly and differently by our participants.

\section{Trustworthiness}

We used several strategies to ensure trustworthiness. First, we engaged in peer debriefing to ensure that we collectively understood instructors' perspectives. Next, we engaged in member checking by soliciting participants' feedback on their own case summaries (Miles et al., 2014). Lastly, we used multiple forms of data (interviews and survey data) as a way to corroborate participants' experiences, triangulate data, and reach data saturation (Miles et al., 2014).

\section{Limitations}

Before moving on to the findings, it is important to note a few key limitations of this study. First, although interviewing faculty instructors allowed us to understand the role of mental health issues in shaping the experiences of those involved in the course, our understanding of the students' experiences were from the perspective of faculty instructors, not the students themselves. Future research should also seek to understand students' perspectives on how mental health issues shape their own experiences studying abroad. Second, our interviews relied on participants' retrospective accounts of what had occurred during their study abroad courses. This was necessary, as it would be impossible to predict possible mental health situations in advance, but does mean that some details of the courses may have been lost or incorrectly described by participants.

\section{Findings}

Consistent with our multiple case study approach (Stake, 2006), we present both overall findings from our cross-case analysis and individual case summaries. We lead with our cross-case findings, which describe our participants' experiences, including the types of mental health needs that occurred and the role that these incidents played in the overall course 
experience for students and faculty members. In the case summaries section, we present four individual summaries where each participant described a different level of severity of mental health issues encountered and varying ways in which those mental health issues played a role in their study abroad course experiences.

\section{Cross-Case Findings}

\section{Students experiencing mental health challenges}

Participants reported encountering a wide range of student mental health needs, from homesickness to ADHD to bipolar disorder. Participants were sometimes aware of students' pre-existing mental health conditions prior to the study abroad course, and other times not. Generally, there was something in the study abroad experience that triggered or exacerbated pre-existing conditions or prompted new issues, bringing the mental health concerns to faculty members' attention. Based on participants' descriptions of the incidents that arose during their study abroad courses, we saw each mental health incident fitting into one of three categories: low, medium, and high, based on the extent to which these mental health issues interfered in the study abroad course.

A number of participants described students whose mental health issues had a relatively minor role in the overall study abroad experience; these generally related to issues of homesickness and mild anxiety. All participants who discussed low-interference issues classified these incidents as falling under the broad category of student "mental health needs," although only a few were related to diagnosed mental health conditions (e.g., clinical anxiety). For example, Franco described a student who had "an extreme attachment to home, family, and life. She used technology... and would be in consistent communication with folks back home rather than coming to terms with the new environment and the study abroad experience." Other participants described varying levels of homesickness and sadness from being separated from friends and family and adapting to a new culture. Diane described how one student in her course had "never been away from home... she never actually had flown on an airplane," and as a result was anxious about flying and being away from home for so long. Stacy described a student who had disclosed that she was on anxiety medication prior to the study abroad experience and had anxiety attacks when participating in some course activities. Stacy stated, 
Our institution requires that all students complete a health form before traveling abroad with any campus courses. In that process students turn in a health form to me and then I review them before submitting them to the institution. So I was aware of the anxieties disorder through the health form collection process.

Stacy awareness of the condition, enabled her the opportunity to make modifications to the course for this student such as ensuring that the student "brought an adequate amount of medication" and "reminding them of the importance of taking their medication particularly when they are in a new and stressful environment" to avoid anxiety-inducing activities.

The above examples, regardless of the severity of any underlying mental health issues, were of incidents that had a relatively minor role in the study abroad course. The next category of examples, however, were those in which participants viewed students' mental health needs playing a negative role in students' experiences. Most of these examples related to somewhat more serious issues of anxiety, along with one example of ADHD. Christopher, for example, described a student who was diagnosed with anxiety. It was immediately noticeable that the student was struggling:

On the second day of the class she was very distraught and concerned with our group being judged for being from the United States, for being loud, she wasn't sure she fit in with the group... it sounded like generalized anxiety, just a lot of concerns about appearance and whether we would fit in and people's reactions to us.

Louisa described a student who had ADHD who engaged in dangerous behaviors that "weren't bad enough to hurt him... but he could have really gotten hurt." She described how he consistently did things that he had been told not to do and went places he had been warned not to go. For example, Louisa explained that when they were riding on ATVs the guides warned the students, "'Do not go ahead of the guide.' And he did, he tumbled, he hurt himself." In another incident, the students came across a pepper plant that Louisa described as "the hottest pepper in the world." The student immediately picked it and "he chewed it and swallowed it... of course then he had to suffer and he was choking." Although this raised Louisa's own stress level substantially, luckily his behaviors never caused serious harm to himself or others.

Finally, a number of participants discussed mental health issues that they described as overwhelming and critical to the student's health and wellbeing. Frequently, these students had diagnosed pre-existing conditions such 
as bipolar disorder, ADHD, anxiety disorders, and autism spectrum disorders, but participants often thought that these underlying conditions were triggered and amplified due to the students' stress being abroad. Dakota described a situation where a student had bipolar disorder and stopped taking her medication, and within hours the student began to act disorientated:

She started asking a lot of questions about quite basic kind of functioning stuff. So how do I turn on the water? How do I? At first it just seemed ok you're jet lagged, culture shocked, etc. But... by day four she was having enormous difficulty sleeping and became... unable to function... Then we would go on field trips and this young woman was having trouble like kind of panic attacks... she would knock on our door in the middle of the night and say I need to go to the hospital... We were really concerned that she was going to have a psychotic break.

John described a student in his study abroad course who had an anxiety attack and then told another student that "she would jump off the bridge" close to their hotel. John further described the aftermath of the incident,

It was pretty strange. There was about two or three days of pretty intense phone calls and so on and then it sort of died down after that... She was in good shape the rest of the trip and I think a lot of the students recognized it as far as going on.

As a result of this experience John stated that,

We do study abroad probably a little more selective now, I do not know how much of this we could have foreseen but I think we tend to want to give people the benefit of the doubt but I think we are both scared off from this experience and that's what made me probably, we would both be more conscious. These examples are similar to other participants' experiences with serious mental health issues that played a significant role in shaping the overall study abroad experience.

Other students' experiences. Consistent with the wide range of mental health needs that arose during participants' study abroad courses, participants described a variety of ways in which those mental health issues played a role in shaping the experiences of other students in these courses. Often it was impossible for the other students to miss the relevant behavior because of the close quarters in which students found themselves. 
In these cases, other students' experiences included interpersonal conflict, stress and distraction, and diversion of the instructors' attention. In one example of interpersonal conflict, Christopher described a situation where the behavior of one student triggered another's anxiety. The student experiencing anxiety told Christopher about the first student's behavior, which he then felt compelled to address with the group. Because it was fairly obvious who had spoken up to the instructor, there was tension between the two students.

Other situations caused more direct stress for other students in these courses. For example, Matthew described a student experiencing significant anxiety while studying abroad, and said that for other students,

It caused at least a little concern... We work in a very tight group and live in a situation where everyone is together and in a facility... so when someone is having a tough time it is very obvious to everyone else.

John described a student exhibiting anxiety and suicidal ideation, which was first noticed by one of the other students in the course. This particular course involved travel to multiple cities, so students were changing roommates every few days. John described how "the dynamic was that as we handed out room keys in every new city, you could sort of tell that the women in the group were like, 'ok, we're gonna end up with student X.'" Although John noted that "I never saw [the other students] necessarily like gang up on this student or make more of it than needed to be made of it," and that he thought that "several students went out of their way to try to include her in things," it was still a distraction and a source of stress for the other students.

Finally, some participants noted that dealing with students' mental health needs diverted their attention from the rest of the class. Matthew explained that "because I was very concerned with the one student, I was not able to give the attention to the rest of the class that I would normally be doing." He went on to note that because he was "basically sitting up with this student all night long," it was almost "impossible to teach my course." John, who as mentioned above was dealing with a student who expressed suicidal ideation, noted,

We really struggled with how to deal with it because it was a distraction to other students on the trip, it was lots of time, attention that we... devoted to the student. And not just initially but sort of continuously over the course of the trip. 
Although most of the student experiences described by participants were negative, there were a few examples of ways that these mental health issues played a positive role in other students' experiences. For instance, Dakota described dealing with a student who had bipolar disorder and had stopped taking her medication, which ended up requiring a great deal of involvement on the part of the instructors to help this student. She recounted how a student later told her that the other students,

saw that it required my co-leader and I to have an extreme degree of patience and so on and they were really moved from seeing that. So we heard that a number of times from students that made them feel better seeing how we were dealing with that in a way that was really not impatient.

Diane recounted a story of a student who had been experiencing extreme homesickness. She described how "it really brought out the best in the other students... everyone tried to make sure that they included this student whenever they were going off on their own or doing anything... It actually helped bring the group together." However, Diane also expressed that "this might be unusual in the sense that this particular mental health case didn't present a problem in terms of slowing us down or having to change our itinerary or anything like that."

In other cases, however, these mental health issues played no role in other students' experiences, typically because the other students were unaware of what was happening. As Pavel explained,

Nobody around knew [that a student had expressed suicidal ideation] and simply because that's not something that you can just broadcast this kind of information, that's wrong, that's not going to help, so instead of letting information out we simply tried to contain it and manage it so we can finish the program.

Emma similarly described a student who had an anxiety disorder, but "she pretty much had it under control" so there was no discernable effect on other students' experiences.

Instructors' experiences. While in some cases there was relatively little effect on the other students participating in the study abroad courses, as those ultimately responsible for the course, participants were acutely aware of all of these situations. A few participants did not discuss any particular role that this had in their own wellbeing or experience in the course, but others discussed how these issues affected them in ways ranging from mild stress 
to seriously contemplating never teaching a study abroad course again. Often participants discussed their unease with their lack of training to deal with mental health issues. As Diane described,

I am concerned I don't know... what kind of behavior would be a trigger or signal to me that this student needs some help right now. So my concern is that students are going to be presenting themselves with mental health issues that are beyond my understanding and my ability to help.

Many faculty members who teach study abroad courses worry about all of the things that can go wrong, and adding mental health issues on top of all of their other concerns can add to the stress they are experiencing. For example, Louisa's experience with a student with ADHD who engaged in dangerous behavior throughout the trip heightened her own anxiety for this student's health and safety. As Christopher explained, having to deal with mental health needs that arose,

made me more anxious, you know, it's another, it's an extra stressor on me to manage all the aspects of the course. You know, I'm responsible for curriculum, budget, transportation, I'm responsible for everything and so just one more thing just makes it more stressful.

Beyond the worry that participants experienced, some participants described the day-to-day burden of assisting students with mental health needs. Dakota described how demanding it was to help a student with bipolar disorder with everyday tasks:

Either me or my co-leader had to be with this young woman anytime, all the time outside of class. The first weekend we had off I had all my meals with her. The laundry, I couldn't say here's how you do the laundry now go do it... I would have to walk with her. She would call her parents and say I don't have any clean laundry and they freaked out. Whooo, it was really challenging.

Pavel described how even though the university's policy was for faculty members and students to stay in separate rooms, after a student discussed the possibility of jumping off of a tall building his female co-instructor ended up sharing a room with that student. He explained, "we literally tried not to leave her unattended" at any time. 
For some participants, their experiences were so stressful that they considered avoiding teaching study abroad courses in the future. For example, Dakota described how this was her first time teaching a study abroad course, and that she and her co-instructor "would not have signed up for this" had they known what might happen. Without adequate training and support, some participants found addressing students' mental health needs to be more than they could or wanted to take on.

\section{Case Summaries}

Case 1: Sarah. Sarah's story represents a relatively less severe form of mental health issue and limited role in instructors' and students' experiences. Sarah discussed her experiences as a first time instructor teaching a study abroad course in Costa Rica. Sarah explained, "I had a student who had pledged a sorority and didn't get in and found out literally before we got on the bus for the airport." Additionally, some of the other students in the group were members of the sorority. Sarah later found out that the student had never flown before and had issues with anxiety. Due to the anxiety and issue with the sorority, the student did not want to continue on the trip. Sarah also noticed that there was some awkwardness with other students, particularly those who were in the sorority. Although it took the student several days to recoup and rejoin the group, Sarah was able to handle this low-impact situation, and it played a minimal role in the overall course.

Case 2: Christopher. Christopher's story represents moderate severity in the type of mental health issue encountered and the role that it had in shaping his and others' experiences in the course. Christopher reported his experiences dealing with a student with "some sort of anxiety or anxiety spectrum disorder" during a study abroad trip to Germany and Poland. The student's anxiety appeared to be triggered by seemingly overwhelming cultural differences between the U.S. and the host countries, as well as concerns with how she and the group were being perceived by host country nationals. As a result of the student's anxiety, tensions grew among the group, causing negative group dynamics. However, Christopher reported by the end of the trip it seemed to have "worked itself out." Although Christopher acknowledged that the student's mental health issue resolved itself, he experienced more stress/anxiety from trying to manage situation. He described that this experience, "made me more anxious... an extra stressor on me to manage all the aspects of the course. I'm responsible for curriculum, budget, transportation, I'm responsible for everything and so just one more thing just makes it more stressful." 
Case 3: Pavel. Pavel's experiences reflect the high-severity end of the spectrum in terms of the type of mental health issue encountered; however, the mental health issue played a relatively minor role in other students' experiences and a relatively moderate role in shaping his own experience. During a course in Japan, one of the students asked Pavel's co-instructor what would happen if she jumped off a building. This suicidal comment led to the student staying with the female faculty member for a portion of the trip as a precaution. Pavel did not think the student truly meant it and that "she was probably seeking attention." Yet, he noted his obligation to address all concerns related to safety or worrying behavior. Because the student had only expressed suicidal thoughts to a faculty member, the other students in the course were unaffected; they did not even know that anything had happened. Pavel explained that the biggest effect was on his female co-instructor who had to share her room with the student and monitor the student's behavior during the day. Pavel explained that his co-instructor "had to be more on her toes... Making sure she didn't go through with the whole intent." He explained that even though he did not think the student would have gone through with it, "we still have that in the back of our heads, you know, that it might really happen... so let's just minimize our excursions."

Case 4: Emma. Emma's experience teaching a course in the European Union demonstrates a high-severity, high-impact mental health situation, with mental health issues playing a major role in the course for the instructor and students. Emma explained, "I had a student that was an alcoholic but she had emotional issues related to alcoholism which we had no clue before she got there." Unfortunately, this student's alcoholism started to cause problems during the course, and "she was found passed out in front of the building one day." When Emma discussed this with the student, she assured Emma that this was "just an isolated incident," but one week later it happened again; that was when Emma and her co-instructor "realized [the student] had some major alcoholic issues."

This particular student's struggles with alcoholism unavoidably played a role in the experiences of other students, as they ended up being responsible for escorting her during the remainder of their time abroad. Emma explained that "there was a heightened sense of 'we have to look out for her'... The students felt uneasy at times especially in the evening because they were worried about her." The students took turns escorting her, but there was some sense that their activities were restricted as a result. For Emma, this was just one part of a "nightmare trip," where she also had a student fall and injure himself on the first night, and she had to send a different student home due to drug use. After all of this, Emma "decided 
maybe I don't want to do this anymore." However, in the end, Emma did decide to continue teaching study abroad courses, and had another course planned for the coming summer.

\section{Discussion}

The findings from this study describe how student mental health issues can play a role in short-term study abroad courses. Findings describe the unique challenges that instructors face in FLSTSA courses with students' mental health issues and point to how student affairs professionals can assist with faculty members' development and skills in addressing these concerns. Reflecting the broader trends in mental health issues in college students (ACHA, 2015), the most common form of mental health issues reported by our participants was anxiety, with several examples of suicidal ideation, bipolar disorder, and substance abuse. Similar to McCabe's (2005) findings, which demonstrated an increase in students' mental health issues abroad, our participants perceived that the stress of travel, being away from home, and adjusting to a new culture exacerbated students' pre-existing mental health conditions and triggered new issues (although new issues were generally relatively minor, such as homesickness and mild anxiety). The wide range of issues that participants classified as "mental health needs" reflect Hunley's (2010) assertion that faculty leaders need to be prepared to address an array of mental health issues. Clinically diagnosed mental health issues are clearly an important consideration, but so are the seemingly minor issues that can still affect the study abroad experience.

Our participants described several incidents where students' mental health issues played a negative role in their overall study abroad experience, as well as in the experiences of other students. Our participants' description of students' experiences paralleled findings by Bathke and Kim (2016) and Hunley (2010) on how students with mental health issues experience psychological and mental stress while abroad. This also reflects insights from ACHA (2015), which discussed how stress can trigger and increase students' mental health issues abroad. Students' mental health issues at times triggered interpersonal conflict between students and within the overall group, leaving other students feeling stressed, distracted, or unsure of how to interact with the student who experienced the mental health issue. Group dynamics were altered due to faculty members having to divert time and energy to assist the student with the mental health issue.

Faculty leaders described several cases in which students' mental health issues played a role in their own experiences as instructors. For instance, participants discussed how students' mental health issues triggered their own 
anxiety and stress. While abroad, faculty members manage the day-to-day aspects of the trip on top of handling students' mental health issues, which participants described as extremely difficult to balance. This caused several participants to feel overwhelmed and worried as often they were juggling the various duties related to being the only "on-the-ground-assistance" as described in previous literature (Keese \& O'Brien, 2011). Second, participants at times felt the lack of training and understanding regarding students' mental health issues was a barrier to them teaching FLSTSA courses. This lack of training and knowledge of student affairs roles (Goode, 2007) affected how participants navigated students' mental health issues within their study abroad courses. Participants also felt students' mental health issues caused an unnecessary burden, leaving some faculty members questioning if they should teach FLSTSA courses again.

\section{Implications}

By providing insight into what is happening on the ground when mental health issues arise during FLSTSA courses, the findings from this study provide important implications for faculty members teaching these courses and the student affairs professionals working to support them. The in-depth description of how mental health issues affected FLSTSA course participants in each of our cases can help faculty members and student affairs practitioners better prepare for these incidents. Our findings point to the importance of faculty members' ability to recognize mental health issues, connect with appropriate in-country and on-campus resources, and manage the overall situation to minimize the potentially negative role of mental health issues in their courses. These topics can provide a foundation for training and support systems for faculty members teaching short-term study abroad courses.

One key way that student affairs professionals can partner with faculty instructors is by serving as co-facilitators of FLSTSA courses (Barr, 2013). A student affairs co-instructor could provide greater focus and expertise on student support, group dynamics, and more individualized follow-up on mental health concerns - duties sometimes outside the realm of faculty instructors' experience or expertise. Overall our findings point to the importance of having more than one instructor accompanying students in FLSTSA courses, as some of our participants relayed that they were unable to focus on teaching their courses when they had to spend so much time dealing with mental health issues.

Additionally, faculty instructors should consider the ways in which they can include student affairs professionals in pre-trip trainings and/or reach out to them for support while abroad. For instance, faculty members can 
have student affairs or counseling professionals and the dean of students (Morse et al., 2017) conduct pre-trip training on code of conduct issues and students' mental health concerns (Barr, 2013). Additionally, faculty members can consult student affairs professionals for in-country resources to address common mental health concerns or possible accommodations for those experiencing mental health issues. Ultimately, strengthening partnerships between student affairs and academic affairs can assist faculty members by increasing their knowledge on the larger mental health issues affecting college students (Barr, 2013).

\section{References}

American College Health Association. (2015). American College Health Association-National College Health Assessment II: Reference Group Executive Summary Spring 2015. Retrieved from http://www.acha-ncha.org/reports ACHA-NCHAllb.html

American Council on Education. (2017). Mapping internationalization on U.S. Campuses: 2017 Edition. Washington, DC Retrieved from https://www.acenet. edu/news-room/Documents/Mapping-Internationalization-2017.pdf

Barbour, J. D. (2015). 'Oh events' for the professor: Studies and stories of religious studies abroad. Teaching Theology \& Religion, 18(1), 88-96. doi:10.1111/ teth. 12267

Barr, T. F. (2013). Utilizing student affairs professionals to enhance student and faculty experiences and mitigate risk in short-term, faculty-led study abroad programs. Journal of International Education in Business, 6(2), 136-147.

Bathke, A., \& Kim, R. (2016). Keep calm and go abroad: The effect of learning abroad on student mental health. Frontiers: The Interdisciplinary Journal of Study Abroad, 27, 1-16.

Brewer, E., \& Solberg, J. (2010). Preparatory courses for students going to divergent sites: Two examples. In E. Brewer \& K. Cunningham (Eds). Integrating study abroad into the curriculum: Theory and practice across the disciplines (pp. 41-63). Sterling, VA: Stylus Publishing.

Creswell, J. W. (2003). Research design: Qualitative, quantitative, and mixed methods approaches (2nd ed.). SAGE.

Creswell, J. W., \& Poth, C. N. (2018). Qualitative inquiry \& research design: Choosing among five approaches (4th ed.). SAGE.

Forum on Education Abroad. (2011). Education abroad glossary. Carlisle, PA: Author. Retrieved from https://forumea.org/wp-content/uploads/2014/10/ Forum-2011-Glossary-v2.pdf

Holm-Hadulla, R. M., \& Koutsoukou-Argyraki, A. (2015). Mental health of students in a globalized world: Prevalence of complaints and disorders, methods and effectivity of counseling, structure of mental health services for students. Mental Health \& Prevention, 3(1-2), 1-4. doi:10.1016/j.mhp.2015.04.003 
Hunley, H. A. (2010). Students' functioning while studying abroad: The impact of psychological distress and loneliness. International Journal of Intercultural Relations, 34(4), 386-392.

Institute of International Education (2018). Open Doors 2017

Executive Survey. Retrieved from https://www.iie.org/Why-IIE/ Announcements/2017-11-13-Open-Doors-2017-Executive-Summary

Jones, S. R., Rowan-Kenyon, H. T., Ireland, S. M. Y., Niehaus, E., \& Skendall, K. C. (2012). The meaning students make as participants in short-term immersion programs. Journal of College Student Development, 53(2), 201-220.

Keese, J. R., \& O'Brien, J. (2011). Learn by going: Critical issues for faculty-led study-abroad programs. The California Geographer, 51, 3-24.

Leggett, K. (2012). Their baggage goes, too. International Educator, 2012(Suppl.), 11-17.

Linder, S., \& McGaha, J. (2013). Building on successes: Reflections from two approaches to study abroad for undergraduate and graduate students. The Educational Forum, 77(3), 379-389.

McCabe, L. (2005). Mental health and study abroad: Responding to the concern. International Educator, 14(6), 52-57.

Merriam, S. B., \& Tisdell, E. J. (2016). Designing your study and selecting a sample. Qualitative research: A guide to design and implementation, 73-104. John Wiley \& Sons.

Miles, M. B., Huberman, A. M., \& Saldaña, J. (2014). Qualitative data analysis: A methods sourcebook (3rd ed.). SAGE.

Morse, C. C., Spoltore, J. D., \& Galvinhill, P. (2017). College/university counseling centers supporting study away: Challenges and opportunities. Journal of College Student Psychotherapy, 31(4), 325-335.

Niehaus, E. Bryan, A., Nelson, M., Briscoe, K. (2020). Addressing students mental health needs in faculty-led study abroad courses. Journal of Student Psychotherapy. Advance online publication. https://doi.org/10.1080/87568225. $\underline{2020.1760160}$

Prince, J., DeRomana, I., Holvey-Bowles, J., \& Hopkins, S. (2006). Best practices in addressing mental health issues affecting education abroad participants. Washington, DC: NAFSA: Association of International Educators.

Prince, J. P. (2015). University student counseling and mental health in the United States: Trends and challenges. Mental Health \& Prevention, 3(1-2), 5-10. doi:10.1016/j.mhp.2015.03.001

Ryan, M. E., \& Twibell, R. S. (2000). Concerns, values, stress, coping, health and educational outcomes of college students who studied abroad. International Journal of Intercultural Relations, 24, 409-435.

Saldaña, J. (2016). The coding manual for qualitative researchers (3rd ed.). SAGE. Spencer, S., \& Tuma, K. (2017). The guide to successful short-term programs abroad. Retrieved from: https://shop.nafsa.org//File//2066 STPA Intro.pdf

Stake, R. E. (2006). Multiple case study analysis. Guildford Press. 
Tuma, K. (2007). Program models. In S.E. Spencer \& K. Tuma (Eds.), The guide to successful short-term programs abroad (2nd ed., pp. 41-45). Washington, DC: NAFSA, Association of International Educators.

Wolf, K., \& Archer, C. (2013). Into the unknown: A critical reflection on a truly global learning experience. Issues in Educational Research, 23(2), 299-314. 